\title{
Experimental Study at Prototype Scale of a Self-priming Free-Surface Siphon
}

\author{
Giovanni De Cesare, Khalid Essyad, Paloma Furlan, Vu Nam Khuong \\ and Sean Mulligan
}

\section{Introduction}

CEVA (Cornavin-Eaux-Vives-Annemasse) is a $16 \mathrm{~km}$ long orbital city rail line which was designed to connect the Geneva main station Cornavin with the French Annemasse train station to the south via the Gare des Eaux-Vives. When completed, the link will allow through running between the main Swiss rail network and the isolated line east of Annemasse in Haute-Savoie. CEVA will run inside double track line tunnels.

The last section between Gare des Eaux-Vives and the Swiss-French border encounters the Foron river course. As a result, the rail link runs into an open trench gallery composed of the Foron river alluvial deposits retaining a high and flowing groundwater table as is highlighted in Fig. 1. The constructed gallery will result in a cut-off of the groundwater, which will have a significant impact on the safety of the structure if equilibrium of the groundwater is not restored.

G. De Cesare $(\bowtie) \cdot$ P. Furlan

EPFL, LCH, Station 18, 1015 Lausanne, Switzerland

e-mail: giovanni.decesare@epfl.ch

P. Furlan

e-mail: paloma.furlan@epfl.ch

K. Essyad · V. N. Khuong

BG Ingénieurs Conseils, Eau \& Environnement, Av. de Cour 61, CP 241,

1001 Lausanne, Switzerland

e-mail: khalid.essyad@bg-21.com

V. N. Khuong

e-mail: vunam.khuong@bg-21.com

S. Mulligan

Department of Civil Engineering, National University of Ireland,

Gaillimh, Co. Galway, Ireland

e-mail: seanmulligan23@gmail.com 


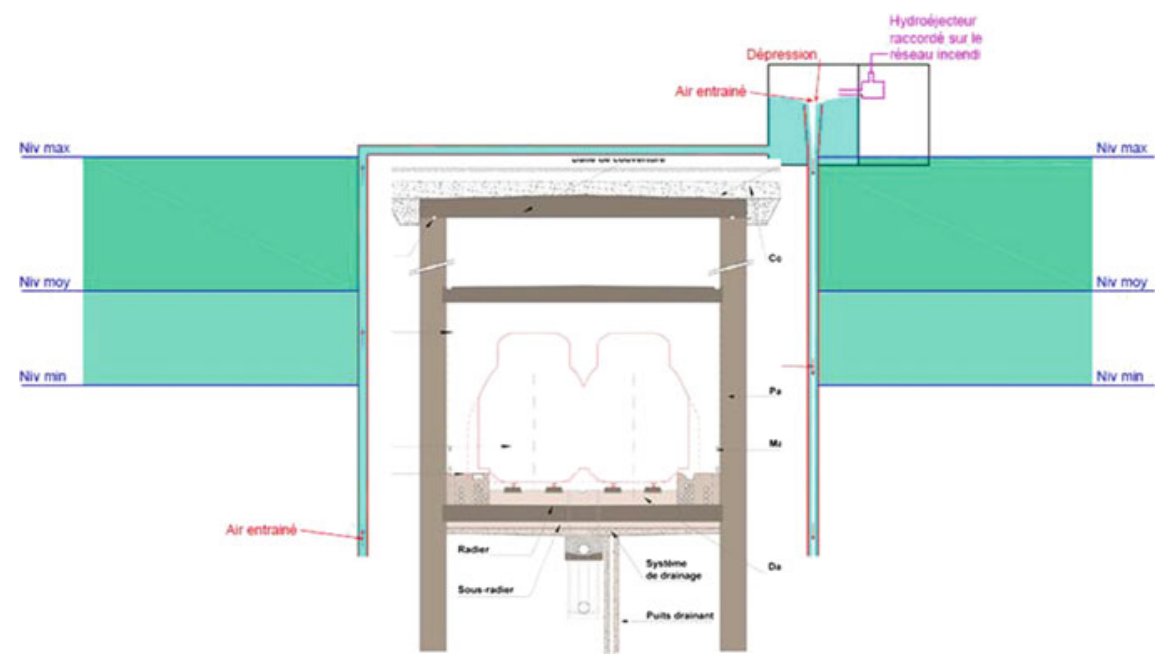

Fig. 1 Cross section of the double track CEVA tunnel with the groundwater water transfer system connecting the two sides of the gallery

In order to solve this issue and reequilibrate the groundwater levels on both sides of the tunnel, an innovative inverse self-priming system was proposed to convey the groundwater thus requiring no continuous pumping and energy requirements. The proposed inverse siphon uses a unique multiphase flow condition of both water and air permitted by a specialized vortex chamber installed in a variable pressure 'sealed box'. The purpose of the air-water flow conditions provided by the vortex is to render the system stall-free in the presence of air entrainment through faulty or damaged pipework under future working conditions.

Owing to the novelty of such an approach to siphoning, as far as the authors are aware, there are no studies available conceiving a reliable design for the system, apart from some work on vortex chambers carried out by [1-4] and [5] in the context of drop shafts for energy dissipation in sewers and hydropower plants. Furthermore, the previous studies were carried out for constant atmospheric pressure conditions, wherein the proposed vortex flow conditions within the sealed box are subject to variable negative pressure conditions. Therefore, a full-scale (1:1) physical model of the system was designed and constructed at the Laboratoire de Constructions Hydrauliques (LCH) of the EPFL, Switzerland. Simulations of such hydraulic structures at full-scale (or almost full-scale) prior to in situ commissioning are regularly required to eliminate scale effects which would otherwise be present in a reduced scale model. Thus, by simulating an inverted siphon in a laboratory environment at full-scale, it was possible to undertake the following objectives as part of this study: 
1. To characterize the initiation and stability conditions of the system.

2. To characterize the limiting operating conditions of the system in relation to the groundwater table levels.

3. To determine the critical conditions of insufficient air entrainment by the downstream flow conditions.

4. To compare the performance data to existing hydraulic equations and draw conclusions on the effect of negative pressure on the flow system.

\section{Experimental Facility}

\subsection{Physical Model}

The experimental facility reproduces the principal components of a self-primed siphon and the surrounding terrain. It is meant to transfer water above the CEVA tunnel in order to control the groundwater table on both sides. Figure 2 shows a schematic representation of the main parts of the model. Different combinations of groundwater levels and discharges can be evaluated to quantify and assess the functioning of the siphon.

The study is carried out at 1:1 scale except for the horizontal conduit. The total height of the model is $6.40 \mathrm{~m}$ high and $5 \mathrm{~m}$ wide. The length of the horizontal pipe was reduced from $15 \mathrm{~m}$ in the prototype to $4.50 \mathrm{~m}$ in model. A spherical valve was used to simulate the range of head losses expected in the full-length pipe.

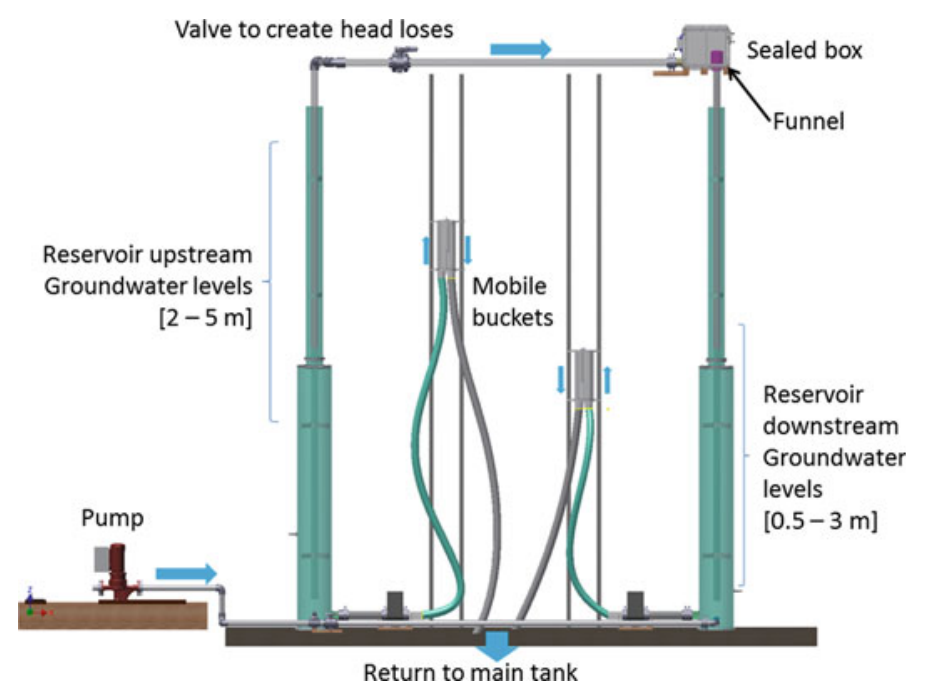

Fig. 2 Schematic representation of the model built 1:1 scale of a self-primed siphon 

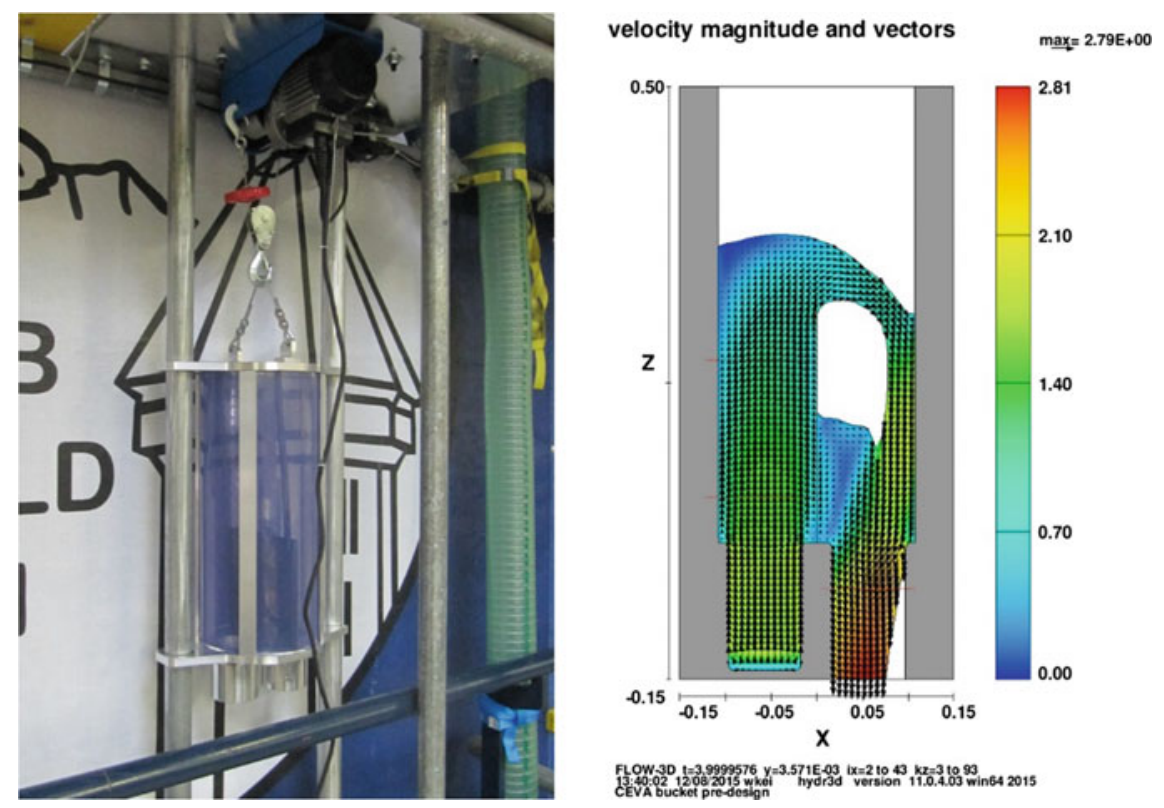

Fig. 3 Image of the mobile bucket and the motor (left). Image of the numerical simulation done with Flow 3D (right)

The upstream and downstream groundwater table levels are reproduced by large circular reservoirs supplied by a pump; levels are regulated by suspended movable buckets (overfall structures) which can be adjusted in height. The buckets were designed using a multiphase model in Flow3D for a maximum discharge of 9 1/s (Fig. 3). The final design resulted in a cylinder of $0.21 \mathrm{~m}$ diameter and $0.50 \mathrm{~m}$ height. The pipe diameter for the inlet and outlet of the buckets was defined from the results of the numerical simulation. An internal wall made from PVC with a $0.20 \mathrm{~m}$ height is placed centrally in the bucket in order to separate the inlet and outlet. Internal tubes for air supply are included in the bucket system. The buckets are attached to a metallic cable and are movable by a motor (Fig. 3). Each bucket can be moved individually and is handled with a manual control. A pump used to supply water to the system and the outlets of the buckets are connected to a main tank from the laboratory generating a closed circuit.

From the main tank, water is pumped to both reservoirs (which simulate upstream and downstream water table levels) through a horizontal pipe with perforations to homogenize the incoming flow. Butterfly valves are installed upstream of the reservoirs to regulate discharge going to each reservoir wherein the reservoir depth is maintained by the buckets which effectively simulates the groundwater level in real conditions. A $90 \mathrm{~mm}$ diameter vertical pipe is contained within the reservoir which serves the purpose of conveying water to the horizontal pipe section and subsequently to the main siphon components. A 'sealed box' comprises the 
main component of the siphon system which is located at the end of the horizontal section. The unique feature of the siphon is that it is a multiphase flow system; both air and water (free-surface flow) are permitted in the siphon without cessation of the siphon itself. This unique feature means that the siphon will not stall when the air is permitted in the system (for example through the inflow of additional air through faulty pipe connections or disturbed pipes in the future).

In order to provide a steady, multiphase flow of air and water simultaneously, use was made of the free-surface vortex where a concentrated region of vorticity results in a local depression of the free-surface, and under ideal conditions of circulation, air entrainment and flow of air through a full air core is maintained [6]. In the sealed box, an off central vertical orifice connected to the downstream vertical pipe ensures that a steady rate of vorticity is generated in the box by the asymmetry of the approach flow from the horizontal pipe (see [7] and [8]). This asymmetric hydraulic arrangement alone was not sufficient to provide enough circulation to maintain a stable vortex air core over the outlet and therefore an additional scroll type vortex chamber was added to ensure that vorticity is focused over the outlet. The scroll vortex chamber was designed according to the depthdischarge equations derived by Mulligan et al. [5] for subcritical approach flows. The scroll chamber walls had a logarithmic spiral geometry as outlined in Fig. 6, wherein the geometry of the logarithmic walls was bounded by the size of the box. The sealed box has dimensions of $0.5 \mathrm{~m}$ long $0.5 \mathrm{~m}$ wide and $0.4 \mathrm{~m}$ high and manufactured from 6 Plexiglas plates joined by screws. The top plate can be removed for atmospheric pressure tests. It was designed to withstand a differential pressure of minus $10 \mathrm{~m}$ water column. In the left wall of the box, there are two air rotameters, a pressure sensor and the inlet connection from the horizontal pipe. In the right wall, there is a connection for a vacuum pump that is required to initiate the siphon. The funnel is connected to the downstream reservoir by a vertical pipe. For this model, two different sizes of funnels were constructed in the workshop of $\mathrm{LCH}$. Both of them were cut out of a PVC block with the shape of a standard overflow spillway in order to improve the adherence of the jet. The design yielded vortex flows where the air core extended deep into the intake. The critical submergence (i.e. the height of vortex collapse) was observed for high discharges. The construction of the model in Plexiglas and transparent PVC permitted visualization during experiments (Fig. 4).

\subsection{Hydraulic Similitude and Instrumentation}

\subsubsection{Hydraulic Similitude}

Due to the 1:1 scale, no scale effects are encountered. For this facility, it was necessary to retain 1:1 scale as the flow system depended on the effects of viscosity, surface tension and gravity simultaneously, i.e., Froude similitude would not be applicable in the pressure conduit sections whereas Reynolds similitude would not 


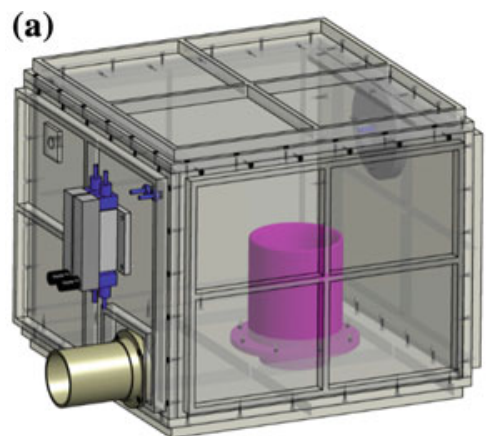

(c)

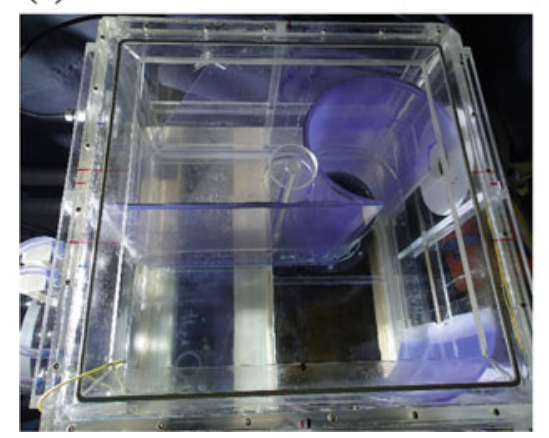

(b)
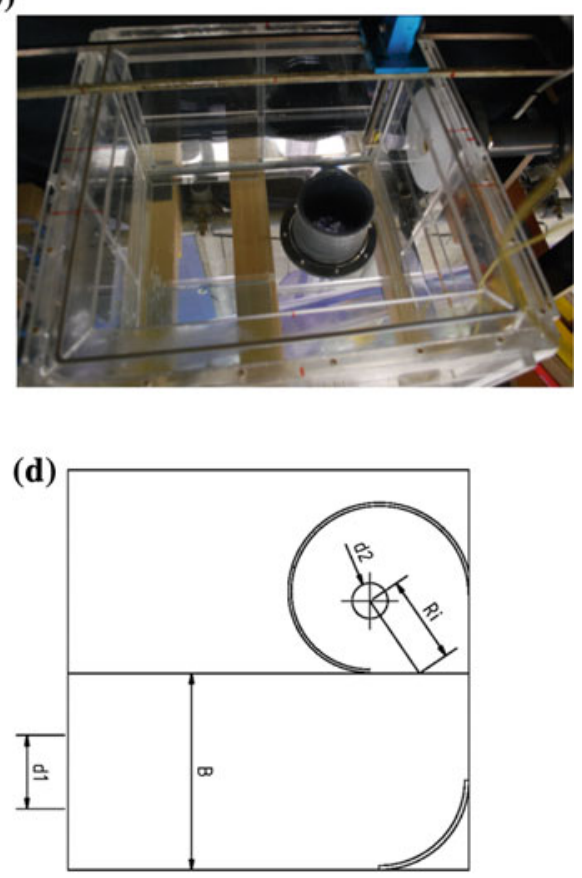

Fig. 4 a 3D schematic drawing of the airtight box showing the position of the inlet and outlet funnel $\mathbf{b}$ image of the installed sealed box $\mathbf{c}$ adaptation with a scroll vortex chamber and $\mathbf{d}$ a line diagram outlining the main components of the logarithmic spiral geometry

be valid in the sealed box. Furthermore, the variable air pressure in the sealed box added higher orders of complexity to the flow problem which rendered reduced scale modelling too risky.

\subsubsection{Instrumentation}

Two flowmeters are placed between the main reservoirs and the mobile buckets to regulate water discharge $Q_{\mathrm{w}}$. Two air rotameters are connected to the airtight box to regulate and measure the required air flow $Q_{\mathrm{A}}$. The position of all the instrumentation is shown in Fig. 5.

The pressure inside the model is measured in various locations with vented gauge pressure transmitters. The main reservoirs have pressure sensors at 1.00 and $0.50 \mathrm{~m}$ from the bottom (upstream and downstream respectively). By measuring the pressure inside the reservoirs, the water level in the reservoir can be determined to assume a hydrostatic pressure distribution. In a lateral wall of the airtight box, there is also a pressure sensor to measure the depression generated by the vacuum pump. 


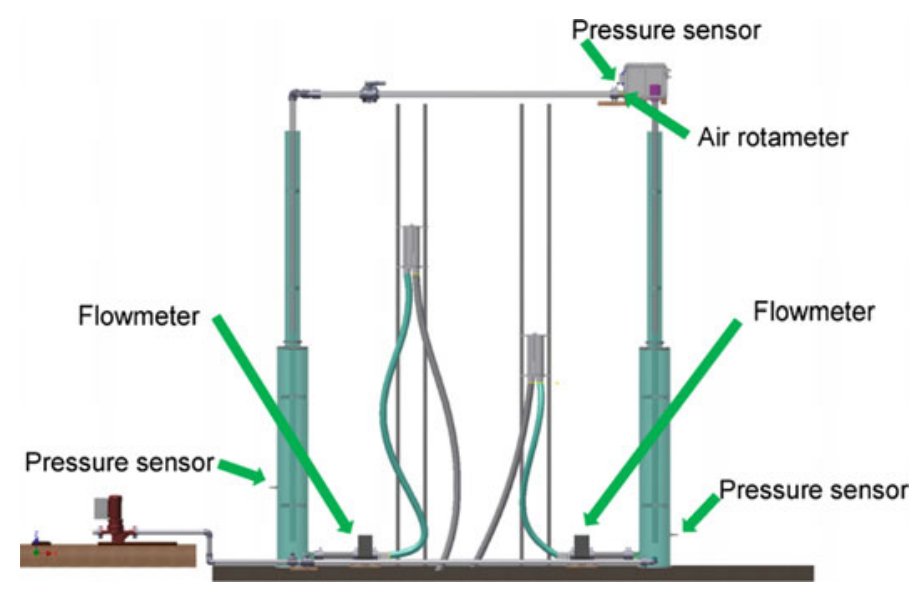

Fig. 5 Schematic drawing with the instrumentation

In order to know the $Q-h$ relation for each funnel, various discharges were measured for atmospheric conditions. The water depth inside the box was measured with an electrical point gauge allowing precise average water-level measurement in a wavy environment. When the box is closed, there are graphical scales to read the water depth on the side walls. The measuring instruments are connected to a computer and through a LabVIEW acquisition program. With this configuration it is possible to record: discharge from both reservoirs, the pressure inside both reservoirs and pressure inside the box at an acquisition frequency is $200 \mathrm{~Hz}$. Air flow is manually controlled with two rotameters.

\section{Parametric Study}

The main parameters under investigation are summarized in Table 1 with their respective range. Their position is visualized in Figs. 6 and 7. The physical model tests can be divided into three phases:

1. Tests with direct supply to the box under atmospheric pressure: this phase will allow characterizing the flow of the funnel (discharge, the height of water). The box is connected directly to the fire network for water supply.

2. Tests with direct supply to the box with negative pressures: the box is closed in an airtight manner, making it possible to measure the flow of air carried by the flow with the aid of the rotameters.

3. Tests with priming of the siphon (by a vacuum pump or venturi ejector functioning with the fire hose discharge): during this phase, the stability of the pre-primed siphon will be characterized as a function of the upstream/ downstream levels as well as the height of water in the sealed box. 
Table 1 List of parameters measured and instrumentation

\begin{tabular}{|c|c|c|c|c|c|}
\hline \multirow[b]{2}{*}{ Symbol } & \multirow[b]{2}{*}{ Parameter } & \multirow[b]{2}{*}{ Instrument } & \multirow[b]{2}{*}{ Precision/error } & \multicolumn{2}{|l|}{ Range } \\
\hline & & & & Min & $\operatorname{Max}$ \\
\hline$H_{1}$ & $\begin{array}{l}\text { Upstream } \\
\text { head }\end{array}$ & $\begin{array}{l}\text { Vented Gauge } \\
\text { Pressure } \\
\text { Transmitter PR-25 }\end{array}$ & $\operatorname{Max} \pm 0.5 \%$ full scale & 0.05 bar & 0.55 bar \\
\hline $\mathrm{H}_{2}$ & $\begin{array}{l}\text { Downstream } \\
\text { head }\end{array}$ & $\begin{array}{l}\text { Vented Gauge } \\
\text { Pressure } \\
\text { Transmitter PR-25 }\end{array}$ & Max $\pm 0.5 \%$ full scale & 0.05 bar & 0.55 bar \\
\hline$Q_{1}$ & $\begin{array}{l}\text { Water } \\
\text { discharge of } \\
\text { tank } \\
\text { upstream }\end{array}$ & $\begin{array}{l}\text { Electromagnetic } \\
\text { flow measuring } \\
\text { system Proline } \\
\text { Promag } 50\end{array}$ & $\begin{array}{l}< \pm 0.5 \% \text { above } 10 \% \text { of } \\
\text { max discharge }\end{array}$ & $0.7 \mathrm{l} / \mathrm{s}$ & $10 \mathrm{l} / \mathrm{s}$ \\
\hline$Q_{2}$ & $\begin{array}{l}\text { Water } \\
\text { discharge of } \\
\text { tank } \\
\text { downstream }\end{array}$ & $\begin{array}{l}\text { Electromagnetic } \\
\text { flow measuring } \\
\text { system Proline } \\
\text { Promag } 50\end{array}$ & $\begin{array}{l}< \pm 0.5 \% \text { above } 10 \% \text { of } \\
\text { max discharge }\end{array}$ & $0 \mathrm{l} / \mathrm{s}$ & $10 \mathrm{l} / \mathrm{s}$ \\
\hline$Q_{\text {fire }}$ & $\begin{array}{l}\text { Water } \\
\text { discharge of } \\
\text { fire hose }\end{array}$ & $\begin{array}{l}\text { Electromagnetic } \\
\text { flow measuring } \\
\text { system Proline } \\
\text { Promag 50 }\end{array}$ & $\begin{array}{l}< \pm 0.5 \% \text { above } 10 \% \text { of } \\
\text { max discharge }\end{array}$ & $\begin{array}{l}\text { Average } \\
\text { min }\end{array}$ & $2001 /$ \\
\hline$p_{\text {fire }}$ & $\begin{array}{l}\text { Pressure fire } \\
\text { hose }\end{array}$ & $\begin{array}{l}\text { Gauge guard type } \\
\text { Z700 PVC-U }\end{array}$ & Not mentioned & & $8-9$ bar \\
\hline$p_{\text {box }}$ & $\begin{array}{l}\text { Pressure } \\
\text { inside box }\end{array}$ & $\begin{array}{l}\text { Vented Gauge } \\
\text { Pressure } \\
\text { Transmitter PR-25 }\end{array}$ & Max $\pm 0.5 \%$ full scale & -0.6 bar & 0 \\
\hline$Q_{\text {air }}$ & $\begin{array}{l}\text { Discharge of } \\
\text { air into the } \\
\text { box }\end{array}$ & $\begin{array}{l}\text { Air } \\
\text { rotameters } \times 2\end{array}$ & $\begin{array}{l}\text { DK } 8002.5 \% \text { above } \\
50 \% \text { of } Q_{\max } \text {, below up } \\
\text { to } 12 \% \text { at } 10 \% \text { of } Q_{\max }\end{array}$ & $201 / h$ & $\begin{array}{l}36001 / \\
\mathrm{h}\end{array}$ \\
\hline$h_{\text {box }}$ & $\begin{array}{l}\text { Water-level } \\
\text { inside box }\end{array}$ & $\begin{array}{l}\text { Scale gauge (for } \\
\text { the closed box) }\end{array}$ & $\begin{array}{l}\approx 1-2 \mathrm{~mm} \text {, depending } \\
\text { on the intensity of waves }\end{array}$ & $0 \mathrm{~m}$ & $0.40 \mathrm{~m}$ \\
\hline$h_{\text {box }}$ & $\begin{array}{l}\text { Water-level } \\
\text { inside box }\end{array}$ & $\begin{array}{l}\text { Electric resistance } \\
\text { point gauge }\end{array}$ & $\begin{array}{l}\text { Theoretical } 0.1 \mathrm{~mm} \\
\text { Practical } \pm 0.5 \mathrm{~mm} \text {, } \\
\text { depending on the } \\
\text { intensity of waves }\end{array}$ & $0 \mathrm{~m}$ & $0.40 \mathrm{~m}$ \\
\hline$T_{\text {air }}$ & $\begin{array}{l}\text { Air } \\
\text { temperature }\end{array}$ & Thermometer & - & & \\
\hline$T_{\mathrm{w}}$ & $\begin{array}{l}\text { Water } \\
\text { temperature }\end{array}$ & Thermometer & - & & \\
\hline$t$ & Time & Chronometer & - & & \\
\hline
\end{tabular}




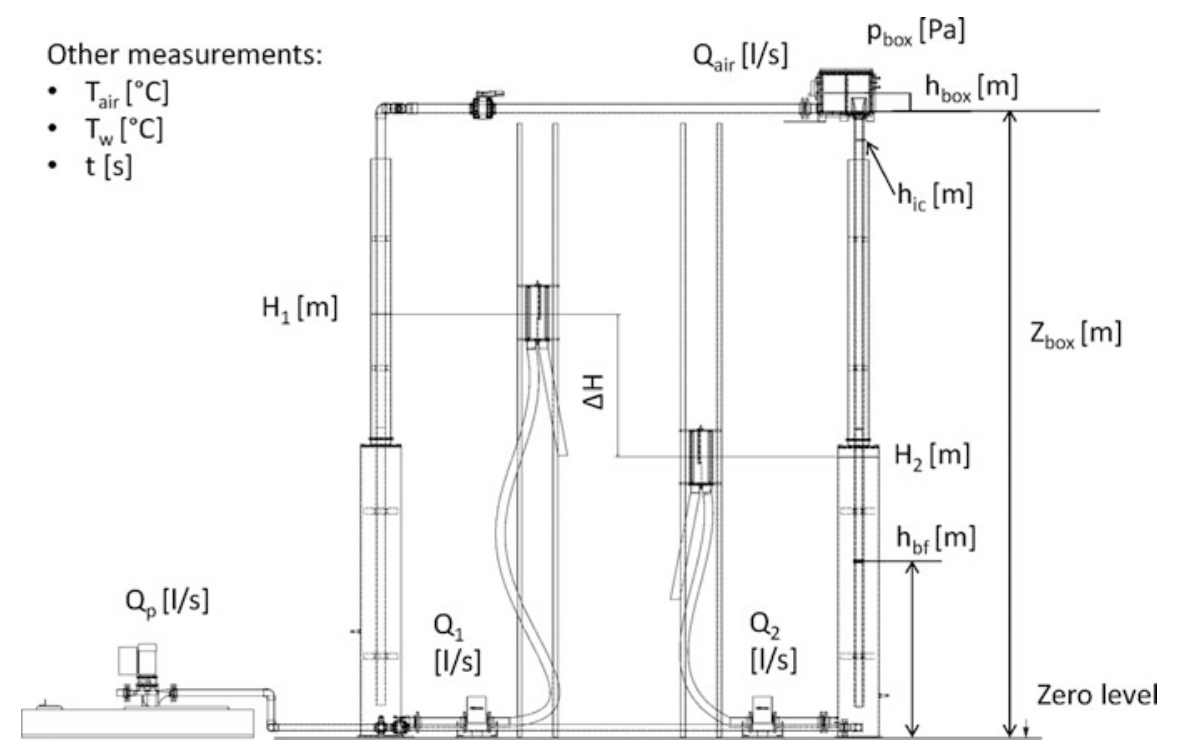

Fig. 6 Schematic representation of parameters measured in the model

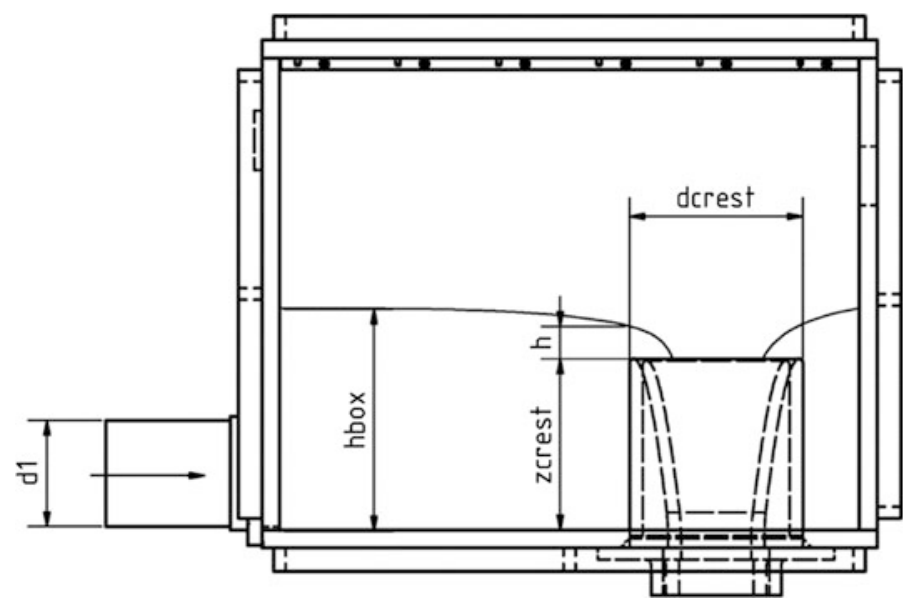

Fig. 7 Schematic representation of parameters measured inside the airtight box — transversal view 


\section{Results and Discussion}

The main results can be introduced as follows:

- The depth-discharge relation for both funnels at free-surface under atmospheric pressure could be determined as a combination of free overfall structure and vortex induced flow similar to a morning glory spillway [9].

- The depth-discharge relationship for both funnels at negative pressure.

- Stability of free-surface vortex flow and performance limitations such as head differences and air supply.

\subsection{Phase 1, Depth-Discharge at Atmospheric Pressure}

The main objective of this phase was to characterize the flow conditions and the depth-discharge relation of the funnels. The firsts run shows that the square initial design of the box induced a highly perturbed free surface, leading to downstream discharge instabilities and sometimes sudden closure (choking) of the impinging jet. The depth-discharge relation measured for the two sizes of funnels are shown in Fig. 8. This figure also compares those measurements with the discharges computed with a classical weir equation (with a discharge coefficient of 0.44 ) and with the semi-empirical vortex equations as defined by Mulligan et al. [5] based on the approach flow geometry. As shown in Fig. 8, there is a good agreement between the experimental and theoretical equations which are clearly divided by a transition point.
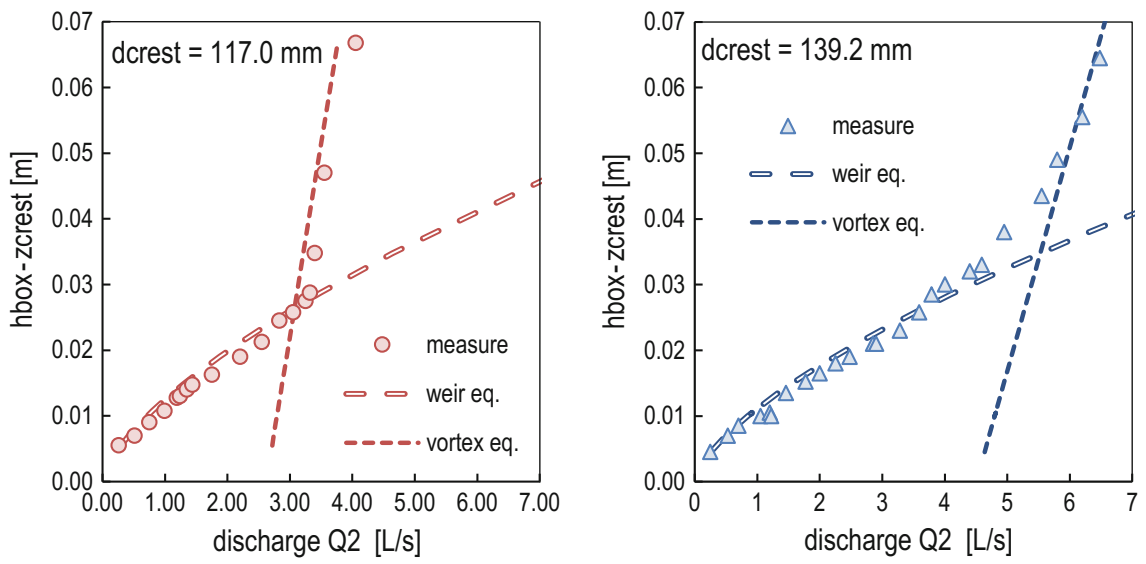

Fig. 8 Depth-discharge relation for both funnels at free-surface under atmospheric pressure, comparison with theoretical classical weir equation and with the vortex equation 
The transition point is characterized by two phases: (A) For low discharge, the weir approach is valid as the flow system is independent of the rotating flow conditions and (B) For higher discharges, the vortex approach fits well with the data, and the funnel is practically not perturbating the vortex flow.

\subsection{Phase 2, Depth-Discharge at Negative Pressure}

To determine the influence of the negative pressure inside the box, depth-discharge relations for both funnels at negative pressure were experimentally determined. The depth-discharge relationship was again measured for the small funnel with pressure inside the box varying from -0.018 bar to -0.157 bar as shown in Fig. 9. As with the tests at atmospheric pressure, the experimental points agree well with the weir and vortex equations. No apparent influence of the negative pressure on the depthdischarge relation was observed for the range of negative pressure investigated. This finding was interesting as it states that (for the measured conditions) free-surface discharges in weirs and vortex flows are independent of atmospheric pressures: thus the flows are only dependent on gravity and the approach flow conditions (see [5]) which can simplify the problem significantly in future analytical work.

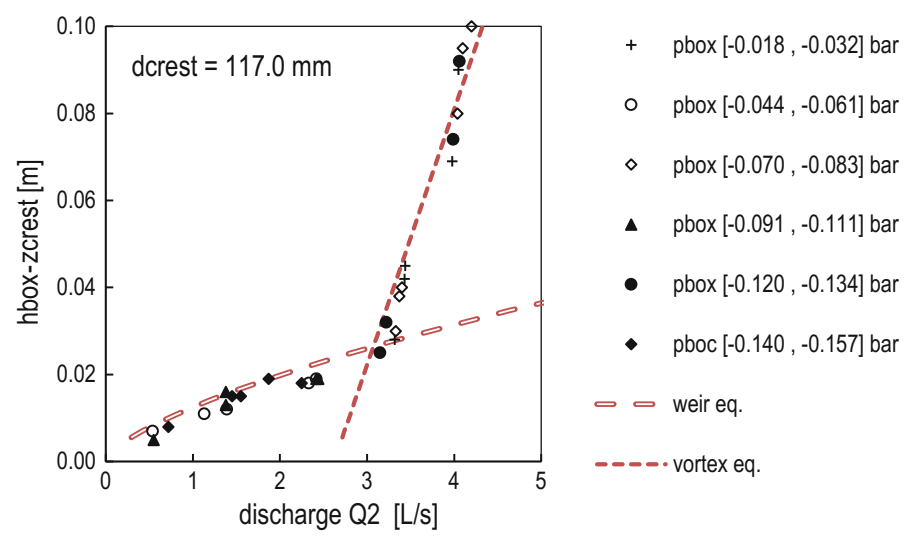

Fig. 9 Depth-discharge relation for the small funnel at free surface under variable negative pressure inside the box, comparison with theoretical classical weir equation and with the vortex equation 


\subsection{Phase 3, Working Limit for Air Entrainment}

The main objective of this phase was to characterize the influence of air inflow on the discharge and ultimately the condition of siphon stall (cessation) or 'loss of prime'. This part of the study was restricted to weir flow conditions.

An initial water discharge was set without air inflow $\left(Q_{2} i\right)$, the discharge $Q_{2}$ was measured while the air inflow into the box $\left(Q_{\text {air }}\right.$, measured at atmospheric pressure) was progressively increased. Figure 10 shows the discharge reduction of the system while air was allowed to enter into the siphon.

The $x$-axis is the volumetric air concentration in the evacuated water flow.

Except for the lowest tested discharge per funnel, the discharge reductions follow a general trend which can be approximated by

$$
\frac{Q_{2}}{Q_{2} i}=\frac{1}{15} \frac{Q_{\mathrm{air}}}{Q_{2}}
$$

The loss of prime (or condition under which the siphon stalls) occurs when the water discharge is no longer of suitable magnitude to evacuate the air downstream. This occurs when the axial velocity in the downstream pipe is lower than approximately $0.4 \mathrm{~m} / \mathrm{s}$. This can be related to the buoyant velocity of air bubbles in water. According to [10], the rise velocity of an air bubble is approximately constant at $0.24 \mathrm{~m} / \mathrm{s}$ for bubble diameters between 1.5 and $4.5 \mathrm{~mm}$; and for a water pressure of less than 1 bar, the variation in bubble diameter is negligible. The main air evacuation parameter is water discharge. For the above-mentioned tests with small discharge, the initial conditions were too close to this air evacuation limit, explaining the strong discharge reduction even with a very small air injection.

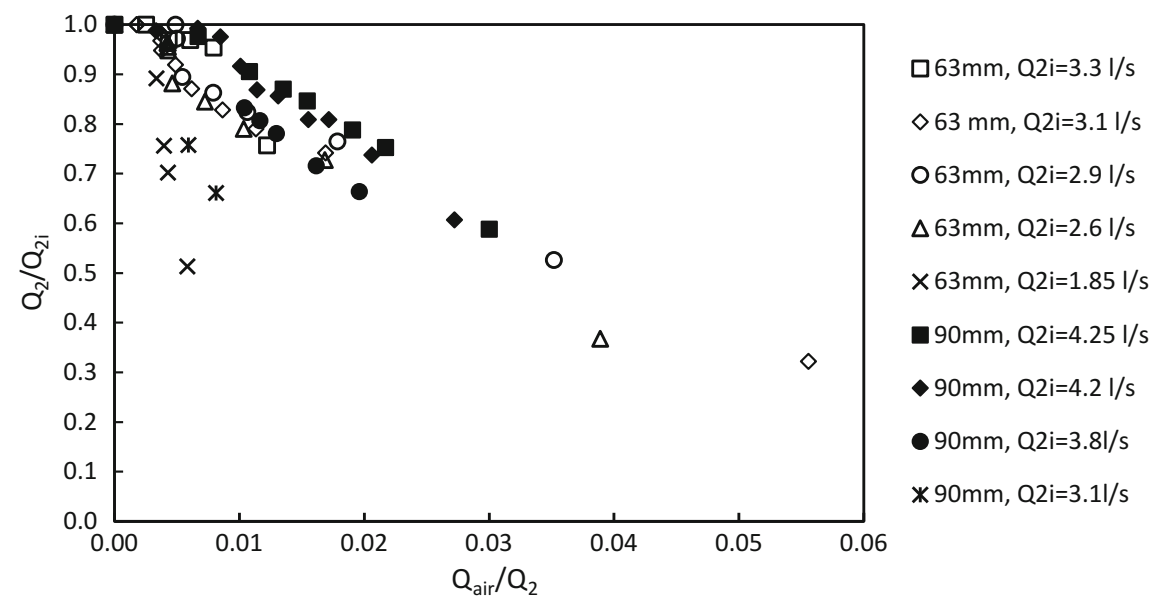

Fig. 10 Relative air inflow and discharge reduction, for weir flow conditions and both funnels 


\section{Conclusion}

The study provided a full-scale simulation of a novel, multiphase self-priming siphon system which is to be installed on the CEVA project to maintain the equilibrium of water tables. Full-scale physical modelling was performed at LCH (EPFL) on the model with a $6.4 \mathrm{~m} \times 5.0 \mathrm{~m}$ vertical foot-print. Full-scale simulation ensured that scale effects could be eliminated when transferring performance data to the in situ system. The results showed that the depth-discharge relationship within the combined vortex chamber and funnel intake consisted of two relationships separated by a transition point. The two relationships agreed closely with available analytical models. The transition point occurred when rotational flow conditions dominated the weir flow under atmospheric conditions. For negative pressure conditions, the depth-discharge equations did not alter stating that free-surface weir and vortex flows are independent of pressure conditions and are only dependent on the approach flow geometry, at least for the range of negative pressures measured in this study. Finally, an empirical relationship for the air flow in the sealed box was defined. The results also suggest that the siphon will cease to operate (stall) when the water discharge is unable to evacuate air bubbles (i.e. maintain air flow) downstream of the intake.

Acknowledgements The presented study is financed by the Swiss Federal Railways as the main stakeholder of the CEVA project.

\section{References}

1. Drioli, C. (1947). Su un particolare tipo di imbocco per pozzi di scarico (scaricatore idraulico a vortice). L'Energia Elettrica, 24(10), 447-452 (in Italian).

2. Ackers, P., \& Crump, E. S. (1960). The vortex drop. ICE Proceedings, 16(4), 433-442.

3. Jain, S. C., \& Kennedy, J. F. (1983). Vortex-flow drop structures for the Milwaukee metropolitan sewerage district inline storage system (No. 264). Iowa Institute of Hydraulic Research, The University of Iowa.

4. Hager, W. H. (1985). Head-discharge relation for vortex shaft. Journal of Hydraulic Engineering, 1015-1020. https://doi.org/10.1061/(ASCE)0733-9429(1985)111:6(1015).

5. Mulligan, S., Casserly, J., \& Sherlock, R. (2016). Effects of geometry on strong free-surface vortices in subcritical approach flows. Journal of Hydraulic Engineering, 142(11), 04016051.

6. Knauss, J. E. (1987). Swirling flow problems at intakes. Rotterdam, Netherlands: A. A. Balkema. 
7. Durgin, W. W., \& Hecker, G. E. (1978, June). The modeling of vortices at intake structures. In Proceedings of the ASCE/ASME/IAHR Joint Symposium on the Design and Operation of Fluid Machinery, Fort Collins, Colo (pp. 12-14).

8. Mulligan, S. (2015). Experimental and numerical analysis of three-dimensional free-surface turbulent vortex flows with strong circulation (Ph.D. dissertation). IT Sligo.

9. Bradley, J. N. (1956). Morning-glory shaft spillways: A symposium: Prototype behavior. Transactions of the American Society of Civil Engineers, 121(1), 312-333.

10. Leifer, I., Patro, R. K., \& Bowyer, P. (2000). A study on the temperature variation of rise velocity for large clean bubbles. Journal of Atmospheric and Oceanic Technology, 17(10), 1392-1402. 